Open Access

\title{
Neuroprotective Effect of Melatonin on Glucocorticoid Toxicity in the Rat Hippocampus
}

\author{
Analía M. Furio, Ramiro Fontao, Nicolás Falco, Juan I. Ruiz, Roberto Caccuri and Daniel P. \\ Cardinali*
}

Departamento de Fisiología, Facultad de Medicina, Universidad de Buenos Aires, Paraguay 2155, 1121 Buenos Aires, Argentina

\begin{abstract}
Dexamethasone has a neurotoxic action on rodent hippocampus. The objective of this study was to examine the extent of neuroprotection exerted by melatonin on that neurotoxic effect. A group of 24 rats received 9 daily subcutaneous injections of $0.5 \mathrm{mg} / \mathrm{kg}$ of dexamethasone. Half of them received $25 \mu \mathrm{g} / \mathrm{ml}$ of melatonin in the drinking water for 10 days. Controls included rats injected with vehicle or rats injected with vehicle plus melatonin in the drinking water. At the end of treatment, the brains were processed for a morphometric analysis, the results being expressed as percent number of abnormal hipoccampal neurons (defined as necrotic cells) per field. Melatonin decreased by $77 \%$ the effect of dexamethasone $(p<0.001)$. A laterality of neurotoxic effect of dexamethasone was apparent in rats that did not receive melatonin (percent of necrotic cells in left and right hippocampus: $32.0 \pm 4.4$ and $19.6 \pm 1.9 \%$, respectively, $\mathrm{p}<0.01$ ). The results indicate a protective effect of melatonin on glucocorticoid neurotoxicity in the rat hippocampus.
\end{abstract}

Keywords: Melatonin, glucorticoid neurotoxicity, hippocampus, neuroprotection.

\section{INTRODUCTION}

The hippocampus is one of the principal targets for glucocorticoid (GC) action in the brain [1-4]. Two types of corticosteroid receptors are present in the rat hippocampus: type I or mineralocorticoid receptor (MR), and type II or GC receptor (GR), which are able to bind GCs with different affinities. High-affinity MRs are heavily occupied under basal, non-stressed conditions while the lower-affinity GRs are only heavily occupied during stress or after GC administration. It has been documented that MR occupancy mediates salutary GC effects (for example, enhancing hippocampaldependent cognition and plasticity), whereas GR occupancy has a number of deleterious effects [1-4]. Prolonged GC exposure induces neuroanatomical changes in the hippocampus, ranging from reversible atrophy of pyramidal CA3 apical dendrites to neuronal loss [4,5]. Hippocampal neuronal damage resulting from continuous exposure to elevated levels of GCs typically occurs over periods longer than 1 week and reflects activation of GRs [6-9]. Even short term treatment of rats with the synthetic GC agonist dexamethasone [10] or with corticosterone potentiates the excitotoxic events of glutamatergic neurotransmission and thus augments hippocampal insult $[11,12]$.

Generation of reactive oxygen species (ROS) presumably plays a major role in decreased cell function and eventual death in rat hippocampus after GC injection [1-4]. Recently, exogenous melatonin was reported as effective in preventing hippocampal neuronal death and cognitive dysfunction that follow maternal deprivation in the developing rat, a situation involving increased $\mathrm{GC}$ levels, over-expression of $\mathrm{GC}$

*Address correspondence to this author at the Departamento de Fisiología, Facultad de Medicina, UBA, Paraguay 2155, 1121 Buenos Aires, Argentina; Tel/Fax: 54-11-59509611; E-mail: dcardinali@fmed.uba.ar receptor genes, and oxidative stress [13]. Indeed, melatonin decreased the expression of GC receptor and increased cell proliferation in the dentate gyrus of maternally deprived neonatal rats [14].

Based on evidence that melatonin is a potent antioxidant and that it has also been demonstrated to reduce the affinity of glucocorticoid receptor in rat brain and to impair GC receptor gene expression $[15,16]$, we carried out the present study, which aimed to assess the occurrence of a neuroprotective effect of melatonin on the degenerative changes of hippocampal nerve cells brought about by dexamethasone treatment in rats.

\section{MATERIALS AND METHODS}

Male Wistar rats weighing 250-300 $\mathrm{g}$ at the beginning of the experiment were kept under light between 0800 and 2000 $\mathrm{h}$ daily and had access to food and water ad libitum. Experiments were carried out in accordance with the European Communities Council Directive (86/609/EEC). A group of 24 rats was treated for 9 days with $0.5 \mathrm{mg} / \mathrm{kg}$ of dexamethasone injected s.c. at $0900 \mathrm{~h}$. Half of these animals received $25 \mu \mathrm{g} / \mathrm{ml}$ of melatonin in the drinking water for 10 days, starting 1 day before dexamethasone treatment. Controls included rats that were injected with saline $(n=11)$ or rats injected with saline plus melatonin $(\mathrm{n}=10)$ in the drinking water.

At the end of treatment all rats were killed by decapitation and the brains were fixed for up to 7 days in $4 \%$ paraformaldehyde. Paraffin-included post fixation brains were cut in antero-posterior sections containing all hippocampal regions of both sides, after separation of frontal and occipital lobes. Sections $(40 \mu \mathrm{m})$ were stained with cresyl violet. Pathological neuronal cells in hippocampal fascia dentate were identified by the following characteristics: nuclear pic- 
nosis and retractions, hyperchromatic cytoplasm, global cellular retractions, vacuolizations, apoptotic body and cellular dissolution. Cells showing a nucleolus in the nuclear compartment were considered normal. The morphometric analysis was performed by counting the number of normal and abnormal neurons (defined as necrotic cells) in the left and right hippocampus. Six fields in each slide were randomly selected on each side and were examined at $400 \mathrm{x}$ using a stereological grill in a Carl Zeiss microscope. Results were expressed as percentage of abnormal cells and were statistically analyzed by a one way analysis of variance (ANOVA) followed by Bonferroni's tests or by a factorial ANOVA.

\section{RESULTS}

Fig. (1A-D), depicts the histological appearance of the hippocampus of rats treated with dexamethasone and receiving or not receiving melatonin in the drinking water. Much less abnormal neurons, as represented by picnotic and clusters of cells, were observed in dexamethasone-treated animals receiving melatonin. The morphometric analysis indicated that the percentage of abnormal hippocampal cells was $26.1 \pm 1.8 \%$ in rats receiving dexamethasone s.c. and $6.0 \pm$ $1.3 \%$ in rats receiving dexamethasone s.c. and melatonin in the drinking water $(\mathrm{p}<0.001)$. The percentage of abnormal
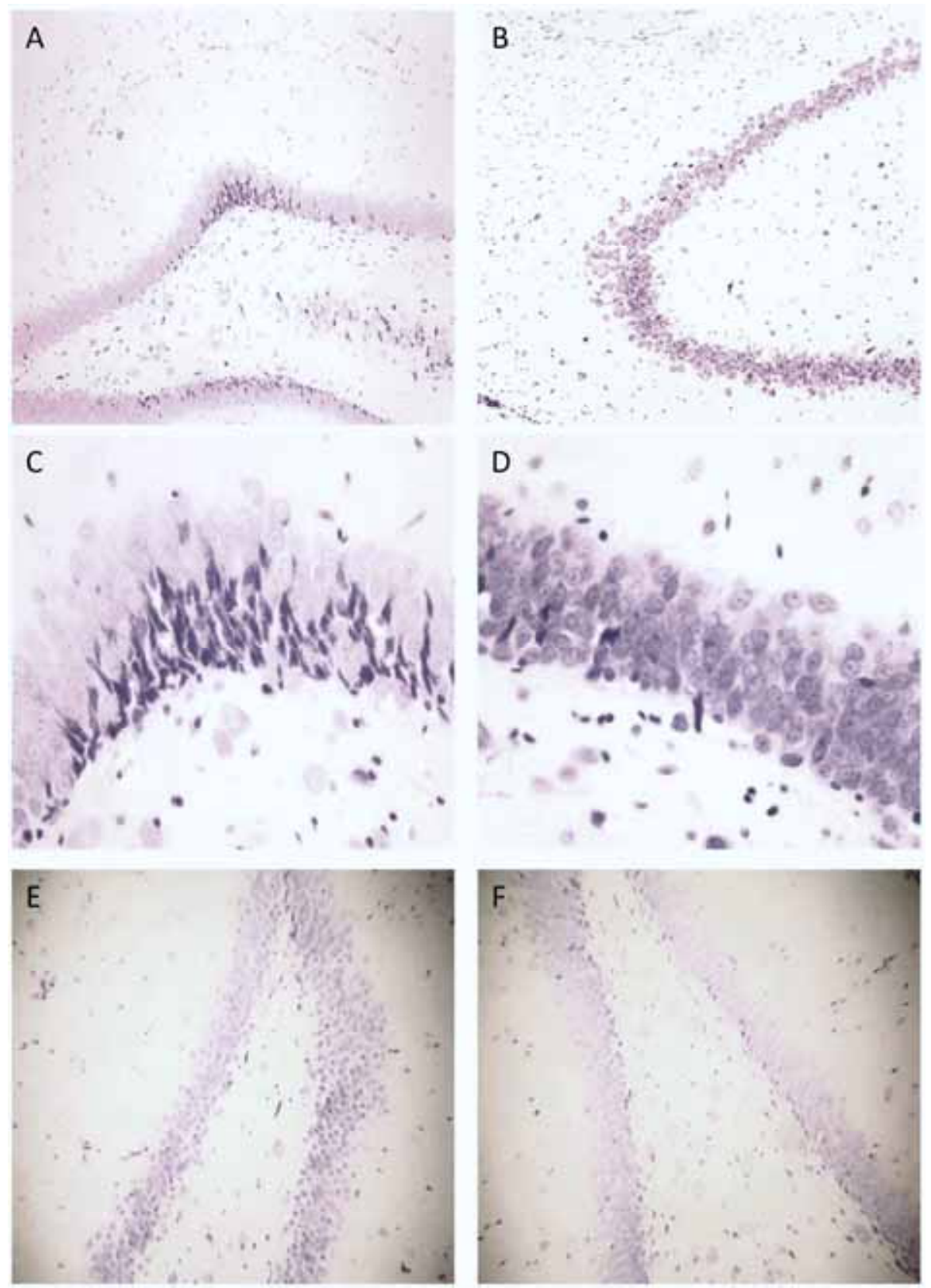

Fig. (1). Plates $\mathbf{A}$ and $\mathbf{C}$ show the histological appearance of the hippocampus of a rat treated for 9 days with dexamethasone. Plates $\mathbf{B}$ and $\mathbf{D}$ show the histological appearance of the hippocampus of a dexamethasone-injected rat receiving melatonin in the drinking water. Neuronal abnormalities (picnosis, clustering of of cells) are greatly reduced in melatonin-treated animals. Plates $\mathbf{E}$ and $\mathbf{F}$ show the histological appearance of the hippocampus of vehicle treated rats receiving or not receiving melatonin in the drinking water, respectively. Cresyl violet staining. Magnification: $250 \mathrm{x}$ for plates A, C, E, F; $400 \mathrm{x}$ for plates $\mathbf{B}$ and $\mathbf{D}$. 
hippocampal cells in rats injected with vehicle and receiving or not melatonin in the drinking water did not differ significantly $(0.73 \pm 0.29$ and $0.1 \pm 0.1 \%$, respectively, Fig. (1E, F).

The distribution of abnormal cells in left and right hippocampus is shown in Fig. (2). A factorial ANOVA indicated a significant hippocampal neuronal degeneration after dexamethasone $\left(\mathrm{F}_{1,83}=214, \mathrm{p}<0.00001\right)$ which was more pronounced in the left hemisphere $\left(\mathrm{F}_{1,83}=10.7, \mathrm{p}<0.002\right)$ and that was impaired by melatonin $\left(\mathrm{F}_{1,83}=81, \mathrm{p}<0.00001\right)$. These conclusions were further supported by the significant interactions "dexamethasone x melatonin", "dexamethasone $\mathrm{x}$ side", "melatonin $\mathrm{x}$ side" and "dexamethasone $\mathrm{x}$ melatonin $\mathrm{x}$ side" detected in the factorial ANOVA $\left(\mathrm{F}_{1,83}=94.6, \mathrm{p}<\right.$ $0.00001 ; 9.9, p<0.002 ; 6.7, p<0.02$ and $7.3, p<0.008$, respectively).

\section{DISCUSSION}

The current results indicate that melatonin shows a neuroprotective effect against the neurotoxic influence of dexamethasone in the rat hippocampus. This chemical induced degeneration of hippocampal nerve cells as shown by their morphological features.

ROS generation may participate in neuronal death caused by GC in rat hippocampus after GC injection [1-4]. Since oxidative stress is recognized as a strong inducer of apopto- sis $[17,18]$ and in view of the remarkable antioxidant activity that melatonin and its metabolites have $[19,20]$, melatonin presumably exerted cytoprotective effects via inhibition of ROS generation and augmentation of the antioxidant defense. However, other possibilities must also be considered. For example, in a study published at the time of submission of the present report, Quiros et al. reported in hippocampal HT22 cells that melatonin prevented glucocorticoid-induced cell death by decreasing receptor translocation to the nuclei in these cells [21].

In a recent study we examined the effect of a daily administration of melatonin for 45 days at two doses $(0.5$ and $1.0 \mathrm{mg} / \mathrm{kg}$ body wt.) on antioxidant status, lipid peroxidation and lipid profile in the brain [22]. Both doses of melatonin caused a significant decrease in brain lipid peroxidation and in the levels of cholesterol, phospholipids, triglycerides and free fatty acids in the brain. Concomitantly, treatment with melatonin augmented the activity of the brain antioxidant enzymes superoxide dismutase, catalase and glutathione peroxidase as well as increased glutathione levels [22].

Melatonin prevented microwave-induced increase in lipid peroxidation of rat hippocampus presumably by strengthening the antioxidant defense system [23]. Likewise, a complete neuroprotection is provided by melatonin against glutamate-induced oxytosis in the HT22 mouse hippocampal cell line [24]. Melatonin reduces pyramidal neuronal death in

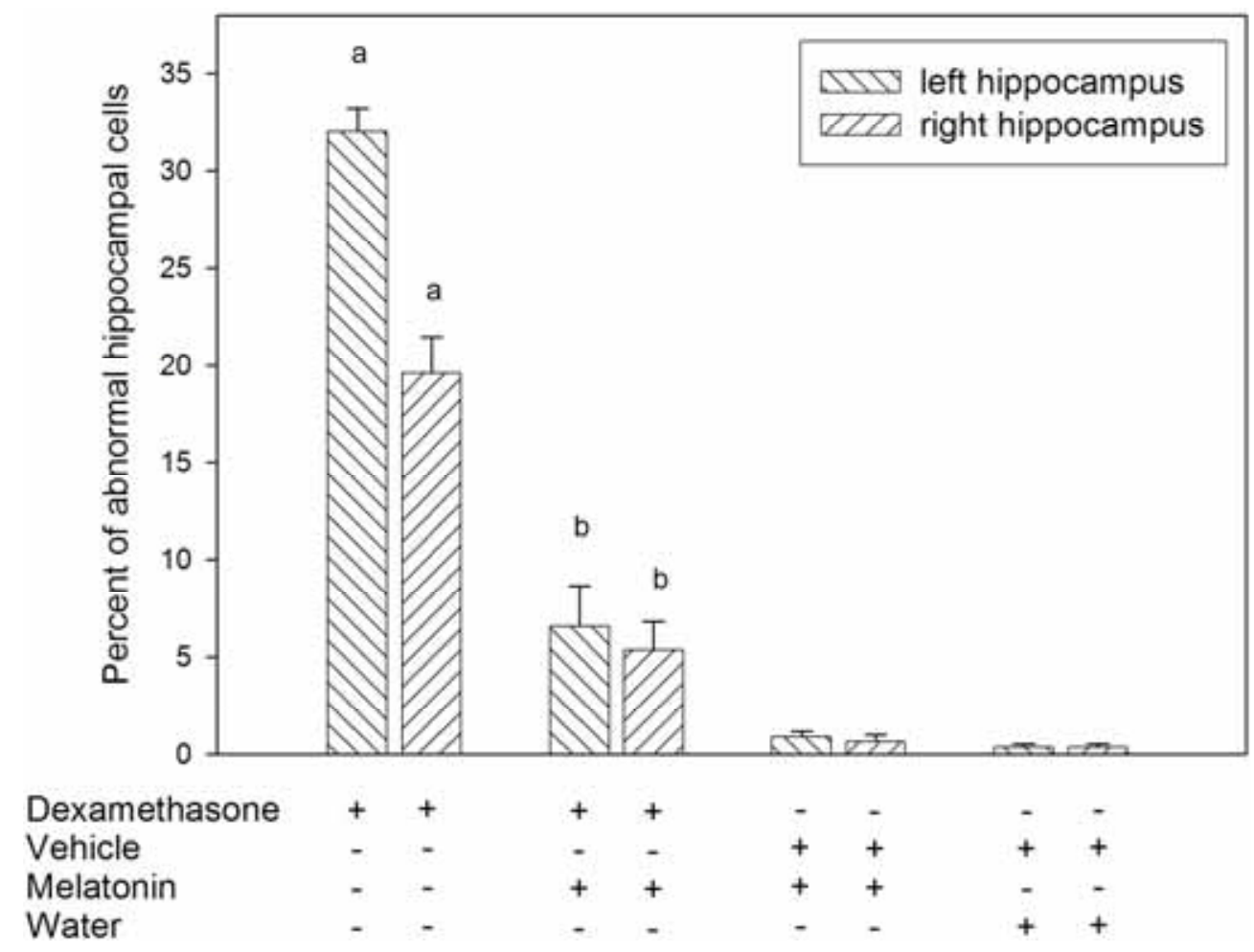

Fig. (2). Percent of abnormal cells in the left and right hippocampus of rats treated for 9 days with $0.5 \mathrm{mg} / \mathrm{kg}$ of dexamethasone injected s.c. at $0900 \mathrm{~h}(\mathrm{n}=24)$. Half of the animals received $25 \mu \mathrm{g} / \mathrm{ml}$ of melatonin in the drinking water for 10 days before and during dexamethasone treatment. Controls included rats injected with saline and receiving melatonin $(n=11)$ or not receiving $(n=10)$ in the drinking water. The morphometric analysis, performed as described in the Methods, indicated a significant hippocampal neuronal degeneration after dexamethasone, which was more pronounced in the left hemisphere and was impaired by melatonin. Letters denote differences in a one way ANOVA, ${ }^{a}$ $\mathrm{p}<0.01$ vs. the remaining means; ${ }^{b} \mathrm{p}<0.01$ vs. rats not injected with dexamethasone of injected with dexamethasone alone. For further statistical analysis, see text. 
the hippocampus and prevents the impairment of place learning and memory in the Morris water maze following global cerebral ischemia [25]. Therefore, the results indicate that melatonin in pharmacological amounts effectively reduces oxidative stress and has a neuroprotective role in the hippocampus.

There is considerable evidence for lateralization of hippocampal function and hemispheric asymmetry in humans. In the rat, studies have reported asymmetries in the thicknesses of layers, the volumes of hippocampal subfields, and the density of cells at specific points along the septotemporal axis. Recently, significant asymmetries were found in the CA1 and CA3/CA2 hippocampal subfields, with the right hemisphere containing 21 and $6 \%$ fewer neurons, respectively [26]. In the present study, hippocampal neuronal degeneration after dexamethasone was more pronounced in the left hemisphere, thus agreeing with previous reports of left dominant asymmetries in the rat brain.

The presence of an atrophied hippocampus is one of the most consistent features of many common psychiatric and neurological disorders, including depression, schizophrenia, bipolar disorder, post-traumatic stress disorder, epilepsy, head injury, and Alzheimer's disease (AD), as well as aging [27-29]. In many instances, e.g. AD, hippocampal atrophy precedes the development of symptoms while in others, there is a temporal relationship between atrophy and symptomatology. Several factors contribute to hippocampal atrophy, stress being one of the most important through mechanisms involving GC hypersecretion [30-32]. High concentrations of GC are found during periods of stress and during the progression of many pathological conditions such as major depression [33] or AD [34]. Hypercortisolemia can contribute to neuronal injury during the course of these and other diseases, particularly with regard to the hippocampus [35]. Therefore, melatonin that effectively curtails the hippocampal damage caused by GC administration, can be proposed as a potentially beneficial agent to prevent memory loss and learning deficits associated with increased GC levels in an early stage of a number of psychiatric and neurological disorders.

Relevant to these previous findings, in a recent study [36], we reported that melatonin treatment was effective as an add-on drug for treatment of mild cognitive impairment, which is an etiologically heterogeneous syndrome characterized by cognitive impairment in advance of dementia and that converts to $\mathrm{AD}$ or other dementia disorders with a rate of approximately $12 \%$ per year. Patients receiving $3-9 \mathrm{mg}$ of melatonin daily in addition to their standard medication for 9 to 18 months showed a better neuropsychological performance in a number of tests than their non melatonintreated counterparts. This coincided with a decrease in mood-related symptoms as assessed by the Beck inventory and with an improvement in subjective global assessment of the sleep/wake cycle [36]. It seems feasible that the efficacy of melatonin to improve the clinical condition in mild cognitive impairment depends partly on the effective neuroprotective effect as indicated by our current findings in the rat hippocampus. Further analysis of functional data (e.g., using Morris water maze or radial maze test) to correlate the neuronal damage in hippocampus with the functionality related to spatial learning and memory in dexamethasone-treated rats would shed light on this point.

\section{ACKNOWLEDGEMENTS}

This study was supported by grants from the Agencia Nacional de Promoción Científica y Tecnológica, Argentina (PICT 14087) and the Universidad de Buenos Aires (ME 075). DPC is a Research Career Awardee from the Argentine Research Council (CONICET).

\section{REFERENCES}

[1] Lucassen PJ, Heine VM, Muller MB, et al. Stress, depression and hippocampal apoptosis. CNS Neurol Disord Drug Targets 2006; 5: 531-46.

[2] De Kloet ER, Joels M, Holsboer F. Stress and the brain: from adaptation to disease. Nat Rev Neurosci 2005; 6: 463-75.

[3] De Kloet ER. Hormones, brain and stress. Endocr Regul 2003; 37 : 51-68.

[4] McEwen BS. Stress and hippocampal plasticity. Annu Rev Neurosci $1999 ; 22: 105-22$.

[5] Haynes LE, Griffiths MR, Hyde RE, Barber DJ, Mitchell IJ. Dexamethasone induces limited apoptosis and extensive sublethal damage to specific subregions of the striatum and hippocampus: implications for mood disorders. Neuroscience 2001; 104: 57-69.

[6] Woolley CS, Gould E, McEwen BS. Exposure to excess glucocorticoids alters dendritic morphology of adult hippocampal pyramidal neurons. Brain Res 1990; 531: 225-31.

[7] Gould E, Woolley CS, McEwen BS. Short-term glucocorticoid manipulations affect neuronal morphology and survival in the adult dentate gyrus. Neuroscience 1990; 37: 367-75.

[8] Hassan AH, von Rosenstiel P, Patchev VK, Holsboer F, Almeida OF. Exacerbation of apoptosis in the dentate gyrus of the aged rat by dexamethasone and the protective role of corticosterone. Exp Neurol 1996; 140: 43-52.

[9] Sousa N, Paula-Barbosa MM, Almeida OF. Ligand and subfield specificity of corticoid-induced neuronal loss in the rat hippocampal formation. Neuroscience 1999; 89: 1079-87.

[10] Supko DE, Johnston MV. Dexamethasone potentiates NMDA receptor-mediated neuronal injury in the postnatal rat. Eur J Pharmacol 1994; 270: 105-13.

[11] Mulholland PJ, Self RL, Harris BR, Littleton JM, Prendergast MA Choline exposure reduces potentiation of $\mathrm{N}$-methyl-D-aspartate toxicity by corticosterone in the developing hippocampus. Brain Res Dev Brain Res 2004; 153: 203-11.

[12] Mulholland PJ, Self RL, Harris BR, Littleton JM, Prendergast MA. (-)-nicotine ameliorates corticosterone's potentiation of N-methyld-aspartate receptor-mediated cornu ammonis 1 toxicity. Neuroscience 2004 ; 125 : 671-82.

[13] Tugyan K, Uysal N, Ozdemir D, et al. Protective effect of melatonin against maternal deprivation-induced acute hippocampal damage in infant rats. Neurosci Lett 2006; 398: 145-50.

[14] Kim MJ, Kim HK, Kim BS, Yim SV. Melatonin increases cell proliferation in the dentate gyrus of maternally separated rats. J Pineal Res 2004; 37: 193-7.

[15] Marinova C, Persengiev S, Konakchieva R, Ilieva A, Patchev V. Melatonin effects on glucocorticoid receptors in rat brain and pituitary: significance in adrenocortical regulation. Int J Biochem 1991; 23: 479-81.

[16] Persengiev SP. Multiple domains of melatonin receptor are involved in the regulation of glucocorticoid receptor-induced gene expression. J Steroid Biochem Mol Biol 1999; 68: 181-7.

[17] Filomeni G, Ciriolo MR. Redox control of apoptosis: an update Antioxid Redox Signal 2006; 8: 2187-92.

[18] Loh KP, Huang SH, De Silva R, Tan BK, Zhu YZ. Oxidative stress: apoptosis in neuronal injury. Curr Alzheimer Res 2006; 3: 327-37.

[19] Reiter RJ, Tan DX, Maldonado MD. Melatonin as an antioxidant: physiology versus pharmacology. J Pineal Res 2005; 39: 215-6.

[20] Zavodnik IB, Domanski AV, Lapshina EA, Bryszewska M, Reiter RJ. Melatonin directly scavenges free radicals generated in red blood cells and a cell-free system: chemiluminescence measurements and theoretical calculations. Life Sci 2006;79: 391-400. 
[21] Quiros I, Mayo JC, Garcia-Suarez O, et al. Melatonin prevents glucocorticoid inhibition of cell proliferation and toxicity in hippocampal cells by reducing glucocorticoid receptor nuclear translocation. J Steroid Biochem Mol Biol 2008; [Epub ahead of print].

[22] Subramanian P, Mirunalini S, Pandi-Perumal SR, Trakht I, Cardinali DP. Melatonin treatment improves the antioxidant status and decreases lipid content in brain and liver of rats. Eur J Pharmacol 2007; 571: 116-9.

[23] Koylu H, Mollaoglu H, Ozguner F, Nazyroglu M, Delibab N. Melatonin modulates $900 \mathrm{Mhz}$ microwave-induced lipid peroxidation changes in rat brain. Toxicol Ind Health 2006; 22: 211-6.

[24] Herrera F, Martin V, Garcia-Santos G, Rodriguez-Blanco J, Antolin I, Rodriguez C. Melatonin prevents glutamate-induced oxytosis in the HT22 mouse hippocampal cell line through an antioxidant effect specifically targeting mitochondria. J Neurochem 2007; 100: 736-46.

[25] Gonzalez-Burgos I, Letechipia-Vallejo G, Lopez-Loeza E, Morali G, Cervantes M. Long-term study of dendritic spines from hippocampal CA1 pyramidal cells, after neuroprotective melatonin treatment following global cerebral ischemia in rats. Neurosci Lett 2007; 423: 162-6.

[26] Lister JP, Tonkiss J, Blatt GJ, et al. Asymmetry of neuron numbers in the hippocampal formation of prenatally malnourished and normally nourished rats: A stereological investigation. Hippocampus 2006; 16: 946-58.

[27] Scarmeas N, Stern Y. Imaging studies and APOE genotype in persons at risk for Alzheimer's disease. Curr Psychiatry Rep 2006; 8: 11-7.
[28] Honea R, Crow TJ, Passingham D, Mackay CE. Regional deficits in brain volume in schizophrenia: a meta-analysis of voxel-based morphometry studies. Am J Psychiatry 2005; 162: 2233-45.

[29] Fossati P, Radtchenko A, Boyer P. Neuroplasticity: from MRI to depressive symptoms. Eur Neuropsychopharmacol 2004; 14 (Suppl 5): S503-S510

[30] Bremner JD. Stress and brain atrophy. CNS Neurol Disord Drug Targets 2006; 5: 503-12.

[31] Duman RS, Monteggia LM. A neurotrophic model for stressrelated mood disorders. Biol Psychiatry 2006; 59: 1116-27.

[32] Miller DB, O'Callaghan JP. Aging, stress and the hippocampus. Ageing Res Rev 2005; 4: 123-40.

[33] Strohle A, Holsboer F. Stress responsive neurohormones in depression and anxiety. Pharmacopsychiatry 2003; 36 (Suppl 3): S207S214

[34] Pomara N, Greenberg WM, Branford MD, Doraiswamy PM. Therapeutic implications of HPA axis abnormalities in Alzheimer's disease: review and update. Psychopharmacol Bull 2003; 37: 12034.

[35] Hoschl C, Hajek T. Hippocampal damage mediated by corticosteroids--a neuropsychiatric research challenge. Eur Arch Psychiatry Clin Neurosci 2001; 251 (Suppl 2): II81-II88

[36] Furio AM, Brusco LI, Cardinali DP. Possible therapeutic value of melatonin in mild cognitive impairment. A retrospective study. J Pineal Res 2007; 43: 404-9.

(C) Furio et al.; Licensee Bentham Open.

This is an open access article distributed under the terms of the Creative Commons Attribution License (http://creativecommons.org/license/by/2.5/), which permits unrestrictive use, distribution, and reproduction in any medium, provided the original work is properly cited. 